\title{
IRIS)
}

\section{Biblioteca da Faculdade de Direito do Recife: contribuições da Política de Preservação à salvaguarda da memória documental}

\section{Faculty of Law of Recife Library : contributions of the Preservation Policy to the safeguarding of documentary memory}

\author{
Karine Gomes Falcão Vilela \\ Mestre em Ciência da Informação pela Universidade Federal de Pernambuco (UFPE) \\ Bibliotecária da Faculdade de Direito do Recife, Centro de Ciências Jurídicas, Universidade Federal de Pernambuco, Recife, \\ Pernambuco, Brasil \\ karine.vilela@ufpe.br \\ Lígia Santos da Silva Rodrigues \\ Mestre em Ciência da Informação pela Universidade Federal de Pernambuco (UFPE) \\ Bibliotecária da Faculdade de Direito do Recife, Centro de Ciências Jurídicas, Universidade Federal de Pernambuco, Recife, \\ Pernambuco, Brasil \\ ligia.ssilva@ufpe.br
}

Resumo: O presente relato de experiência apresenta as contribuições que a adoção de uma política de preservação trouxe à rotina de atividades desenvolvidas na Coleção Especial da Biblioteca da Faculdade de Direito do Recife. A implementação da política foi construída para atender as necessidades de acesso, uso e conservação de obras antigas, raras e valiosas, algumas das quais pertencentes ao acervo fundador. Destaca que a política de preservação, na perspectiva da Ciência da Informação e estudos de Memória, vai além do uso de técnicas por incorporar uma postura institucional que viabilize tanto o acesso e uso da informação sem perder de vista a conservação dos suportes documentais da memória. Descreve as ações de seleção, conservação, catalogação/inventário e digitalização que sistematizadas compõem um instrumento de salvaguarda e gerenciamento de coleções necessário a manutenção do acesso e uso da informação numa biblioteca pública universitária. Destaca a relevância dos registros sobre as atividades desempenhadas para uma documentação, como um modo complementar aos procedimentos de conservação, vez que poderá subsidiar ações futuras.

Palavras-chave: Preservação de acervos. Salvaguarda de coleções. Política de preservação. Biblioteca da Faculdade de Direito do Recife. Coleções Especiais.

\begin{abstract}
The present experience report presents the contributions that the adoption of a preservation policy brought to the routine of activities developed in the Special Collection of the Library of the Faculty of Law of Recife. The implementation of the policy was built to meet the needs of access, use and conservation of old, rare and valuable works, some of which belong to the founding collection. Emphasizes that the preservation policy, in the perspective of Information Science and Memory studies, goes beyond the use of techniques by incorporating an institution-al posture that enables both access and use of information without losing sight of the conservation of the documentary supports of memory. It describes the selection, conservation, cataloging/inventory and digitalization actions that systematized make up an instrument for safe-guarding and managing collections necessary to maintain access and use of information in a public university library. Highlights the relevance of the records on the activities performed for documentation, as a complementary way to the conservation procedures, since it can subsidize future actions.
\end{abstract}

Keywords: Preservation of collections. Safeguard collections. Preservation policy. Library of the Faculty of Law of Recife. Special Collections. 
Biblioteca da Faculdade de Direito do Recife: contribuições da Política de Preservação à salvaguarda da memória documental Karine Gomes Falcão Vilela e Lígia Santos da Silva Rodrigues

\section{Introdução}

Uma Biblioteca Jurídica destinada aos acadêmicos do Curso Jurídico de Olinda, mas prioritariamente Pública onde "todos os Cidadãos [brasileiros], [e] estrangeiros serão admitidos indistinctamente, prestar-se-ha qualquer livro, ou manuscripto, que pedirem, e lhes fornecerá tinta e pennas, para fazerem seos apontamentos.". (RODRIGUES, 2017, p. 137). Essas são algumas das orientações previstas, desde 1831, no primeiro Regimento da Biblioteca da Faculdade de Direito do Recife ${ }^{2}$. Percebe-se que a disponibilidade em promover o livre acesso dos leitores à informação celebrada, na atualidade, como novidade e um dos paradigmas da "era pós-custodial", constituiu um dos pilares da Biblioteca de Direito desde sua instituição.

Da inauguração, em 1830, no Convento São Francisco em Olinda, até a instalação definitiva em 1912, no Palácio da Faculdade de Direito do Recife, a Biblioteca de Direito passou por várias transferências. Instalada em locais precários sob condições improvisadas que rendiam queixas constantes tanto dos estudantes sobre o lamentável estado de conservação do acervo, quanto da administração pública que considerava um desperdício o gasto com uma coleção de obras inúteis. Inútil é apenas um dos adjetivos pejorativos atribuídos aos livros danificados, nos ofícios trocados entre bibliotecários, diretores da Faculdade e o governo central (RODRIGUES, 2017, p. 146). O acervo é referido constantemente como uma coleção de velhos alfarrábios, obras truncadas, livros sujos, carunchosos.

Na Biblioteca de Direito, em 1856, aos exemplares infestados pelas traças lhes restava a venda ou a fogueira, como se lê na autorização concedida por João Alfredo ao diretor da Faculdade de Direito: "Fica V. Sa autorisado, como pede em seo officio de 17 do mezpassado, a mandar vender em hasta publica os livros da bibliotheca d'essa Faculdade que se achão estragados pela traça, fazendo queimar os que não tiverem compradores." 3

A possível estranheza que ações extremas como essas provocam atualmente, findam-se quando se consideram dois aspectos:

O primeiro é o contexto em que foram aplicadas, meados do século XIX, com escassez de recursos e desconhecimento de técnicas de preservação, presume-se que tratava-se de uma escolha entre o risco premente de contaminação de todo o acervo, ou a perda de alguns poucos exemplares. 
Mas qual a quantidade desses "poucos"? Quais eram os títulos? Foram tais obras efetivamente vendidas ou queimadas? Quanto a estes questionamentos, até onde foi pesquisado, não há registro

O segundo aspecto que permite olhar com cuidado às medidas adotadas no passado para o descarte de livros é que apesar de toda sorte de adversidades, ainda assim parte considerável do acervo inicial, formado por obras já antigas à época, foi mantido na Biblioteca. A existência desses volumes, suscita mais um questionamento: $\mathrm{O}$ que contribuiu para a permanência desses exemplares antigos na Biblioteca de Direito até o século XXI?

Para além do conteúdo informacional (imaterial), poderia ter ocorrido uma seleção com base na forma (materialidade) dos livros: a qualidade do papel e da tinta em que foram impressos, as técnicas artesanais de confecção? Ou teriam sido considerados aspectos ligados a sua edição como o impressor, a tiragem a circulação da obra?

É importante ressaltar que essas hipóteses são limitadas, uma vez que o acesso ao passado nos chega enquanto discurso, pois não é possível restaurar o vivido em sua integridade. Esse discurso é materializado nos documentos, que por sua vez, como defende (LE GOFF, 2003, p.533535) "não é qualquer coisa que fica por conta do passado, é produto da sociedade que o fabricou segundo as relações de forças que aí detinham o poder". Logo, não existe documento neutro, tampouco inócuo. De modo que "todo documento deve ser submetido a uma crítica mais radical".

Visto a ausência de registros capaz de subsidiar as respostas aos questionamentos: Como? Quando? E quais, as estratégias determinantes, no século XIX, para a manutenção de certos livros antigos no acervo da Biblioteca de Direito. Se do passado as respostas não estão disponíveis, então, registre-se as metodologias de preservação adotadas no presente. Este trabalho se dedica em descrever as ações de conservação desenvolvidas, a partir de 2005, no acervo histórico da Biblioteca da Faculdade de Direito do Recife.

O registro dessas ações é, em certa medida, um modo complementar aos procedimentos de conservação, como argumentam (PINHEIRO; GRANATO, 2012, p. 130), que entendem, que “outras formas de proteção para os bens culturais são essenciais para sua preservação e se relacionam com a pesquisa e a documentação desses bens".

O presente relato de experiência tem como objetivo apresentar as contribuições da política de preservação adotada na Biblioteca de Direito para a salvaguarda da memória documental da Instituição, a descrição de aspectos técnico-científicos aplicados se reveste de especial importância, por dar a oportunidade de registrar para o futuro essa experiência. 
Biblioteca da Faculdade de Direito do Recife: contribuições da Política de Preservação à salvaguarda da memória documental Karine Gomes Falcão Vilela e Lígia Santos da Silva Rodrigues

Por Patrimônio Cultural denomina-se "aqueles bens que se destacam dos demais por um processo de significação, que se formaliza quando da escolha para que façam parte desse conjunto". De modo que são objetos de interesse da preservação têm, portanto, em comum sua natureza simbólica, todos são símbolos e todos têm um potencial de comunicação, seja de significados sociais, seja de sentimentais.

$\mathrm{Na}$ Biblioteconomia, como na Ciência da Informação (CI), o livro (informação registrada) é ao mesmo tempo fonte e objeto de estudo. Enquanto memória, a informação registrada recebe atributos que transitam em diversos domínios, sob diversos conceitos.

No âmbito da CI, área temática deste estudo, a memória é vinculada aos conceitos de patrimônio e documento e em especial sob o enfoque da conservação, também denominada preservação, vez que para Monteiro e Carelli (2008 apud ZAMMATARO; MONTEIRO, 2017, p. 21): "a memória refere-se ao conjunto das informações registradas, ou seja, aos documentos e representações que podem ser consultados e servir de memória social ou de longo prazo".

Aqui se parte do pressuposto que a preservação da memória documental requer antes mesmo da adoção de procedimentos técnicos, a adoção de uma postura que reflita no modus operandi do profissional, uma forma de agir guiada não por si só, mas pelos objetivos e missão institucional.

O conceito de memória permeia vários domínios e sob vários pontos de vistas em particular, na CI, questiona-se o que significa em termos pragmáticos estudar à informação ou conhecimento à luz da Memória? Para Vera Dodebei e Azevedo Netto (2017), a incorporação da memória pela CI, embora ainda frágil em termos epistemológicos, começa a incorporar ao arcabouço teórico e metodológico da CI os estudos culturais que dão sustentação às investigações sobre a Memória.

Pelo viés dos estudos culturais de produção de conhecimentos no espaço-tempo contemporâneo se permite retomar os debates sobre a importância da Memória. Nesse contexto, a CI, que se voltava apenas aos documentos científicos passa a ter um interesse nos objetos produzidos no cotidiano das relações sociais: cartas, fotografias, esculturas religiosas, objetos exvotos tanto como peças únicas (memória individual), quanto na forma de coletâneas institucionalizadas (memória coletiva), o que vai implicar em pesquisar não mais e tão somente o que acontece no âmbito da informação científica, mas também nos mais variados contextos culturais de produção.

Com esses estudos culturais se têm uma ampliação do conceito de "documento", que incorpora além de artefatos produzidos pelo ser humano, também, objetos naturais e mesmo seres 
vivos que podem, num determinado contexto, assumir uma "função documental" Araújo (2014) a exemplo, do antílope de madame Briet.

\section{A Coleção especial da Biblioteca de Direito}

Antes de caracterizar a Coleção Especial (CESP) da Biblioteca de Direito é necessário esclarecer que esta não é a única a compor o acervo da Instituição. Há também a Coleção Circulante que também requer cuidados na preservação do acervo. Neste trabalho, entretanto, serão detalhadas as contribuições, resultado da política de preservação aplicada ao acervo histórico depositado na CESP, para a Biblioteca de Direito.

A Coleção Especial da Biblioteca da Faculdade de Direito do Recife é formada por uma diversidade de tipologias documentais distribuídas no acervo bibliográfico e na Hemeroteca com os periódicos (revistas e jornais). Dentre livros, periódicos, folhetos e manuscritos, pode-se identificar por meio de registros arquivísticos e literários aqueles que iniciaram o acervo quando da criação da Biblioteca em 7 de dezembro de 1830.

O decreto sancionado pelo imperador D. Pedro I estabeleceu a Biblioteca do Courso de Sciencias Jurídicas e Sociaes ${ }^{5}$ a primeira Biblioteca Pública de Pernambuco ${ }^{6}$. O acervo inicial formado a partir de doações: uma compulsória (Congregação do Oratório de Pernambuco, 1830), outra advinda de subscrição voluntária (acadêmicos e Lentes do Curso, 1831) e da contribuição governamental (Biblioteca Nacional e Pública da Corte, 1832).

Como grande parte das Bibliotecas Universitárias, centenárias, o acervo da Biblioteca de Direito, também foi formado a partir de doações e com o passar dos anos a esse acervo inicial foram agregados outros tipos de documentos produzidos pela própria Faculdade, fruto de pesquisas, como teses, dissertações, artigos, e ainda a esses, foram incorporados mais obras advindas de outras instituições em processo contínuo.

Grande parte das obras que chegaram à Biblioteca de Direito já eram antigas para época, como aquelas vindas da Congregação do Oratório $^{7}$ com títulos publicados nos séculos XVI ao XVIII. Algumas, eram intituladas de velhos alfarrábios inúteis, nas palavras de seus contemporâneos oitocentistas. Outras, resistiram ao tempo e chegaram ao século XXI e consideradas, numa perspectiva atual, como verdadeiros documentos-monumentos. De modo a comprovar que a 
história de um livro não inicia na biblioteca onde ele está. Todo livro tem uma história pregressa, que nos remete a lugares, trajetos, leitores e mesmo a sua gênese e construção declara Vilela (2020).

Como os antecedentes de alguns dos livros que estão na CESP, a exemplo das obras com temática jurídica como o exemplar de Syntagma Secundum Ordinem Institutionum Justiniani, escrito por Johann Gottlieb Heineccius título recomendado no primeiro ano dos Cursos Jurídicos para a disciplina de Direito Natural e no segundo ano para Direito das Gentes registra Rodrigues (2017).

Um outro exemplo é a obra Regulae juris tam civilis, quam pontificii, quae a clarissimis jurisconsultis variè conscripta, ac collectce hactenus circumferebantur, trata-se de um modelo exemplar de preservação, publicado em 1571, encaminhado à Biblioteca do Curso Jurídico de Olinda, em 1830, quando da extinção da ordem religiosa do Oratório de São Felipe Nery.

Regulae juris tam civilis [...] foi publicada na cidade de Lyon na França, celeiro de debates em torno do tema jurídico, um dos últimos títulos publicados pela casa editora do livreiro e impressor Jacques Guinta famoso pela tradição editorial e especializado em Direito.

A permanência desse exemplar quinhentista no acervo da Faculdade de Direito é enigmática por se tratar de um livro já antigo quando o Curso e a Biblioteca foram criados, possivelmente pode ter sido considerado à época, um livro raro ou mesmo especial, por ser uma obra com mais de duzentos anos. Não é possível saber com precisão, quais as motivações responsáveis pela sobrevivência do exemplar que provavelmente poderia ser considerado ultrapassado para o ensino. Com base na documentação administrativa, a hipótese levantada é que se tratou de uma decisão de natureza pragmática, pois procurou-se selecionar e conservar livros jurídicos, mas também selecionaram obras que serviriam para compor uma memória da notoriedade bibliográfica do Curso Jurídico de Olinda.

É importante destacar que em meados do século XX é possível encontrar documentação da própria Biblioteca sobre a existência de livros e periódicos raros e valiosos, do ponto de vista cultural e financeiros. Iniciativas de conservação anteriores remontam ao final do século XIX quando identificados ${ }^{8}$ pedidos de encadernação, com a participação do bibliotecário na indicação do modelo e do material a ser usado nos livros. Não foram localizados registros, porém, de que esta prática tenha sido adotada para fins estéticos ou de conservação.

De volta ao século XX foi a partir desse período que os livros raros ganharam estantes apropriadas a guarda e segurança. Os exemplares recebiam o carimbo em caixa alta inscrito 'Obra Rara' e na catalogação era mencionada a raridade da obra. 
No século XXI, a partir de 2005, foram realizados projetos de: conservação e restauro, catalogação/inventário; aquisição de equipamentos de segurança e mobiliário; adaptação de espaços para acomodar os acervos de forma mais segura e de acordo com critérios técnicos de conservação, e ainda a instalação do Laboratório Conservação e Restauro - LABOR (em 2010) especializado em papel, com o objetivo de manter a conservação do acervo histórico da Biblioteca.

Entre os anos de 2005 a 2018 foi possível tratar por meio desses projetos aproximadamente 10.000 volumes de obras raras e valiosas ${ }^{9}$ distribuídas em coleções como a dos livros que deram origem ao acervo da biblioteca - Coleção dos [padres] Oratorianos, coleções particulares de personalidades na área jurídica, a saber: a coleção do jurista Tobias Barreto de Menezes constituída por exemplares em alemão, francês e latim, datadas do século XIX. Na Coleção de Tobias é possível encontrar diversos exemplares, com dedicatórias de personalidades da Escola do Recife, movimento pioneiro de caráter crítico e cunho literário, filosófico e jurídico; os projetos também contemplaram coleções de documentos manuscritos: livros de assinaturas, inventários, textos literários, Coleções de Leis do Império do Brasil e do Reino como as leis Afonsinas, Filipinas e Manuelinas; obras como a Prosopopea, de Bento Teixeira (1601), o Castrioto Lusitano, de Raphael de Jesus (1679), o Katecismo Índico da Língua Kariris, de Bernardo Nantes (1709) e a coleção de periódicos raros: a Edinburg Review (1802-1868) em 181 volumes, a Quartely Review em 53 volumes e a Wetminster Review em 121 volumes, esses três títulos compuseram o acervo fundador da Biblioteca desde 1834, além da Revista Acadêmica, publicação da própria Faculdade editada, desde 1891.

Os remanescentes do acervo inicial da Biblioteca de Direito estão reunidos na Coleção Especial e são considerados obras raras e valiosas quer por seu conteúdo quer pelos elementos extrínsecos, quer pela memória documental que representam ao histórico da Instituição.

\section{O porquê de uma política de preservação}

Em “A memória vegetal e outros escritos sobre bibliofilia”, Umberto Eco (2010), parte da premissa que "os livros não morrem só por conta própria." Com o objetivo em identificar quais as ameaças iminentes a integridade dos livros, ele levanta uma questão, aparentemente simples, mas que é primordial para o planejamento de qualquer Política de Preservação de Acervos: "De que devemos salvar os livros?". 
Na obra o próprio Eco (2010, p. 45) responde: desde "o sepultamento em lugares úmidos e inóspitos" até o vandalismo de alguns apreciadores de obras raras porque, "é difícil despedaçar uma catedral, ou a Capela Sistina, mas os livros são ameaçados até por quem os ama tanto (ou tão pouco) que deseja possuí-los nem que seja a retalho”.

Como se vê, os riscos são muitos quando se trata de segurança e preservação de acervos, sobretudo em bibliotecas e suas coleções especiais. Na salvaguarda desses acervos, há uma série de medidas que podem ser implementadas, daí a importância de planejar uma política de preservação que produza subsídios também para tomadas de decisões (LINO; HANNESCH; AZEVEDO, 2003, p. 59-76).

Jayme Spinelli e Pedersoli Júnior (2011) elencaram dez agentes de deterioração de acervos, quais sejam: forças físicas; criminosos, fogo, água, pragas, poluentes, luz e radiação UV e IR, temperatura incorreta, umidade relativa incorreta e dissociação. E propuseram medidas para prevenilas além de ações para tratá-las.

Para esses autores a segurança de acervos está ligada ao conceito de gerenciamento de riscos e deve ser integrada a gestão do patrimônio. São atividades que precisam ser constantemente avaliadas e a equipe sistematicamente envolvida e continuamente informados e consultados durante o processo de gerenciamento de riscos afirmam Spinelli e Pedersoli (2011).

O conceito de Preservação comumente abrange os princípios da Conservação e Restauração com vistas a salvaguardar e proteção do patrimônio, de modo a prever o desenvolvimento de políticas e procedimentos a serem adotados e cumpridos pela instituição detentora das obras. Tratase do monitoramento ambiental, que engloba técnicas preventivas de inspeção do controle climático, das instalações físicas, do manuseio, do acondicionamento, do transporte e da exposição do material informacional (CONWAY, 2001. p. 14).

Por Conservação entende-se o conjunto de intervenções diretas que podem ser realizadas na estrutura física do material, para fins de tratamento, de forma a impedir, retardar ou inibir a deterioração ocasionada pela falta de preservação, englobando ações de: higienização, desinfestação de insetos ou microrganismos e a realização de reparos.

Já a Restauração é o tratamento que envolve intervenções mecânicas, químicas, estruturais e/ou estéticas, com vistas a revitalizar um material informacional ou bem cultural. O tratamento deve respeitar, ao máximo, a integridade e as características históricas, estéticas e formais do material ou bem original. 
Como forma de ampliar a ação da Preservação para além da integridade física das obras, deve-se inserir a catalogação como instrumento de segurança de acervos enquanto inventário bibliográfico. A descrição bibliográfica constitui importante meio para o conhecimento detalhado das obras, portanto, aliado na salvaguarda do patrimônio. E ainda mais, a Preservação engloba não apenas o uso de técnicas e procedimentos, mas vai além e expõe uma postura, quer profissional ou institucional, que conduz as ações de conservação e restauro de maneira a atingirem um objetivo comum, a salvaguarda da informação, objeto de estudo da Ciência da Informação.

Nas palavras de Lino, Hannesch e Azevedo (2003, p. 59-76), o inventário e análise da coleção é um dos primeiros passos de uma política de preservação, de modo que a partir dela o gestor passa a ter real posse do acervo. Assim cada item é individualizado e seu real valor passa a ser reconhecido. Essa etapa contribui para tomada de decisão quanto às prioridades e no que tange à segurança das coleções, dando condições para articular medidas de salvaguarda.

Em sua tese de doutorado, Raphael Greenhalgh (2014) cita as diretrizes previstas Guia de segurança do acervo da Association of College e Research Libraries (ACRL/RBMS) Guidelines que instrui o conhecimento do acervo como ferramenta de proteção e recuperação de obras, pois quando um acervo é descrito de forma diligente, torna-se mais fácil a identificação e recuperação dos exemplares objeto de roubo ou furto. Dessa forma, a representação descritiva, além de útil à identificação das obras, é imprescindível para garantir a segurança dos acervos e proteger o direito de propriedade (PINHEIRO, 2003, p. 9-33).

A digitalização se apresenta como mais um recurso de preservação e conservação dos volumes, pois a partir dela as obras são poupadas do manuseio. De acordo com Conway (2001) o universo digital transformou o conceito da preservação tradicional. Assim, em vez de se garantir apenas a integridade física do objeto, passa-se a especificar a geração e manutenção do objeto digital, cuja integridade intelectual é sua característica principal.

O grau de confiabilidade referente à preservação ou memória ainda está muito atrelado às mídias analógicas, argumenta (DODEBEI, 2013, p. 227), (...) não se sabe quais serão os suportes da informação que existirão no futuro, mas sabe-se, com certeza, que ambas as mídias analógicas e digitais devem ser preservadas. Nesse contexto a preservação digital envolve o “... planejamento, alocação de recursos e aplicação de métodos e tecnologias para assegurar que a informação digital de valor contínuo permaneça acessível e utilizável” (HEDSTROM, 1998, p. 189-202). 
Apresentadas em linhas gerais as principais ações de salvaguarda aplicadas à preservação do acervo histórico da Biblioteca, ações essas que subsidiam as atividades relativas ao tratamento técnico submetido aos documentos, serão descritos a seguir as contribuições da Política de Preservação à salvaguarda da Coleção Especial.

\section{Contribuições da política de preservação à salvaguarda da coleção especial}

Há um consenso entre pesquisadores que, independente de qual agente degradante se quer proteger o acervo bibliográfico, sabe-se que a adoção de apenas uma medida preventiva não é suficiente para garantir a preservação dos documentos. Diante disso, ações de conservação e restauro realizadas na Biblioteca de Direito nos últimos anos confluíram para o estabelecimento de uma política de preservação que tem contribuído para a salvaguarda e uso da informação e seus suportes de maneira integrada e responsável.

Se por um lado dispor de raridades bibliológicas causam entusiasmo e enobrece o acervo, por outro, trazem a inquietante dualidade entre a conservação versus o manuseio dos volumes. Essa situação torna-se ainda mais delicada quando na avaliação de cursos de nível superior pelo Ministério da Educação as "obras raras" são excluídas do escopo dos acervos e com isso enfraquece a justificativa para investimentos nesse tipo de material.

Sabe-se que a preservação de um acervo raro e especial é "muito mais fácil de conseguir se os objetos nunca forem manipulados e se forem mantidos em aposentos escuros, com umidade relativa (UR) e temperaturas constantes" (BRADLEY, 2001. p. [15]-34). Por outro lado, o "não uso" por si só não garante que as obras estejam seguras quer do roubo, quer de agentes biológicos e das intempéries climáticas.

A adoção de medidas restritivas de acesso e manuseio dos documentos, mesmo com vistas a conservá-los, em uma instituição pública de ensino e pesquisa, não parece ser o modelo mais adequado a ser defendido, embora em alguns casos medidas de restrição de acesso sejam, por vezes, necessárias. Bibliotecas públicas, por sua natureza e finalidade, têm a missão de franquear o livre acesso aos livros e fomentar a pesquisa e essa dualidade: entre o preservar e liberar o manuseio, traz insegurança ao profissional que lida com a conservação e guarda de coleções. Para sanar essa e tantas outras dificuldades enfrentadas na rotina de bibliotecas universitárias e ainda mais na gestão de coleções especiais é que a política de preservação deve ser implementada. 
Biblioteca da Faculdade de Direito do Recife: contribuições da Política de Preservação à salvaguarda da memória documental Karine Gomes Falcão Vilela e Lígia Santos da Silva Rodrigues

As atividades realizadas há anos de forma dispersa na CESP por equipes de bibliotecários e restauradores, quando passaram a ser sistematizadas, deram origem a Política de Preservação da Biblioteca de Direito. Houve sem dúvida uma economia de recursos materiais e melhor operacionalização de rotinas e prazos que antes esbarravam na ingerência das ações.

A política de preservação desenvolvida na Biblioteca de Direito, vale ressaltar, não está impressa no formato de um documento único com objetivo e diretrizes nele pré-estabelecidos. A política de preservação é uma postura profissional que vem institucionalizar por meio de documentos, protocolos e ações setorizadas, porém integradas, para atender a missão da Biblioteca, que é promover o acesso, a disseminação e a atualização da informação para apoio às atividades de ensino, pesquisa e extensão da UFPE.

A principal meta dessa política foi sistematizar as ações desenvolvidas de maneira dispersas e sem nenhuma organicidade e que passaram a ser guiadas a partir das seguintes diretrizes: 1) Registrar e divulgar documentos, serviços e ações; 2) Sistematizar e integrar o fluxo das atividades técnicas de biblioteconomia e conservação/restauração, e, 3) Institucionalizar às estâncias superiores os procedimentos desenvolvidos pelas equipes da biblioteca e laboratório de conservação e restauro.

As diretrizes acima apresentadas têm auxiliado no processo de comunicação entre bibliotecários e restauradores processo esse fundamental na identificação de prioridades e na tomada de decisões, têm também alicerçado a gestão da biblioteca no melhor direcionamento de recursos e planejamento. O registro dessas ações contribui de forma decisiva no presente para a sua institucionalização e para que a memória de procedimentos, ações e posturas profissionais não sejam negligenciadas no futuro.

Nessa perspectiva, considera-se tão importante quanto adoção de uma política, o registro das ações adotadas por meio de documentos institucionais ou acadêmicos quer de âmbito interno ou externo à instituição de maneira que formalize e legitimem tais ações no contexto em que foram implementadas, além do registro constituir um recurso de gestão e planejamento para as atuais gerações e de memória para equipes vindouras.

Para atender a primeira diretriz: 1) Registrar e divulgar documentos, serviços e ações; foram publicados os seguintes trabalhos: 
Biblioteca da Faculdade de Direito do Recife: contribuições da Política de Preservação à salvaguarda da memória documental Karine Gomes Falcão Vilela e Lígia Santos da Silva Rodrigues

1.1 Curadoria da Coleção Especial da Faculdade de Direito do Recife: Relato de experiência. In: Conferência sobre Tecnologia ${ }^{1}$, Cultura e Memória, 2015, Recife. O artigo descreve todo ciclo da curadoria digital aplicada na CESP da Biblioteca de Direito, que vale esclarecer não deve ser confundida com a Política Preservação, a Curadoria Digital é uma das estratégias que integra a Política de Preservação da Biblioteca de Direito;

1.2 Coleção das obras raras e valiosas da Faculdade de Direito do Recife: preservação de bens culturais. In: XVII Seminário Nacional de Bibliotecas Universitárias - SNBU, 2012, Gramado- RS. Descreve as ações desenvolvidas ao longo do projeto Preservação da Coleção de Obras Raras e Valiosas da Faculdade de Direito do Recife, financiado pelo Banco Nacional de Desenvolvimento Econômico e Social (BNDES), realizado nos anos 2010 e 2011, com o objetivo de catalogar, desinfestar, higienizar, restaurar, acondicionar e inventariar as obras raras e valiosas existentes na Sala Gláucio Veiga da CESP. O projeto do BNDES fomentou a criação do Laboratório de Conservação e Restauro - LABOR; e no tratamento técnico de 1.612 exemplares que compõem o acervo da referida sala;

1.3 Obras raras e valiosas da Biblioteca da Faculdade de Direito do Recife: Repertório bibliográfico dos séculos XVI ao XX. Recife: Gráfica Liceu, 2011. 69 p. Catálogo com a descrição detalhada das obras tratadas da Sala Gláucio Veiga no Projeto do BNDES;

1.4 Critérios de raridade aplicados à coleção especial da Faculdade de Direito do Recife: Sala Rui Barbosa In: X Encontro Nacional de Eventos Raros - ENAR, 2012. O artigo detalha a construção dos critérios de raridade aplicados na seleção das obras depositadas na CESP, essas obras compuseram o acervo da Sala Rui Barbosa (SRB), que reúne obras raras e valiosas datadas dos séculos XVIII ao XX;

1.5 Obras raras e valiosas da Biblioteca da Faculdade de Direito do Recife: repertório bibliográfico dos séculos XVIII ao XX. Recife: Editora Universitária da UFPE, 2011, 243 p. Percebe-se nesse catálogo que a equipe da Biblioteca se profissionaliza nas publicações, pois além do registro do ISBN do catálogo, há a impressão na editora da UFPE. Nele estão descritos as atividades

\footnotetext{
1 Curadoria da Coleção Especial da Faculdade de Direito do Recife: Relato de experiência. In: Conferência sobre Tecnologia, Cultura e Memória, 2015, Recife. Curadoria em Rede: estratégias para gestão, preservação e acesso... Anais [...], 2015. Disponível em: http://www.liber.ufpe.br/home/wp-content/uploads/2016/09/15-Curadoria-da-Colecaoespecial_Vilela.pdf. Acesso em: 23 jan. 2021.
} 
Biblioteca da Faculdade de Direito do Recife: contribuições da Política de Preservação à salvaguarda da memória documental Karine Gomes Falcão Vilela e Lígia Santos da Silva Rodrigues

de conservação das obras raras e valiosas da Coleção Especial que foram implementadas por meio em projeto financiado pelo Conselho Federal Gestor do Fundo de Defesa de Direitos Difusos do Ministério da Justiça - CFDD/MJ em parceria com a Universidade Federal, a Faculdade de Direito e o Sistema de Bibliotecas. Graças a esse projeto os documentos, antes dispersos no acervo da biblioteca e suas dependências, foram reunidos na Sala Rui Barbosa que é uma extensão física da Coleção Especial e fora reformada para abrigar parte das obras raras e valiosas da Biblioteca da Faculdade de Direito do Recife. Ao final do projeto, foram catalogados 1821 títulos distribuídos em 2513 volumes; e

\subsection{Curso Gerenciamento e Tratamento Técnico de Coleções Bibliográficas}

Especiais (GTTCBE), realizado entre os dias 14 e 18 de março de 2016, no Auditório Tobias Barreto da Faculdade de Direito do Recife. Evento organizado por uma equipe de bibliotecários da própria Faculdade e de outras instituições. A capacitação foi ministrada pelo Prof. Fabiano Cataldo de Azevedo (Unirio), com o intento em promover uma compreensão do conceito, papel e desenvolvimento organizacional das coleções especiais. Com ênfase na definição e importância do papel das coleções especiais, dos usuários, o desenvolvimento de coleções, o acesso intelectual e bibliográfico, a preservação, relações com os doadores.

Esses trabalhos documentam, apresentam resultados dos projetos desenvolvidos publicados e apresentados em eventos profissionais submetidos a apreciação por pares que contribuem para o enriquecimento das atividades desenvolvidas.

$\mathrm{Na}$ Sistematização das Atividades Técnicas que compõe o segundo item das diretrizes desenvolvidas na Política de Preservação da Biblioteca de Direito que buscam integrar o fluxo das atividades de biblioteconomia e conservação/restauração, foram adotadas as seguintes rotinas de trabalhos divididas em cinco etapas respectivamente: Seleção dos documentos; Conservação e/ou Restauração; Catalogação/Inventário; Digitalização; Guarda e Manutenção.

\section{Primeira Etapa - Seleção dos documentos}

Diante de tão grande volume de documentos torna-se impossível contemplar todo o acervo com as atividades previstas na política de preservação. De modo que as obras e as coleções são selecionadas a partir de demandas de pesquisa ou de projetos. Esse procedimento dá origem a uma lista de demandas que é controlada em documento excel tanto pelo bibliotecário da Coleção Especial como pelos restauradores. Tudo feito de forma muito simples, porém eficiente para gerar 
Biblioteca da Faculdade de Direito do Recife: contribuições da Política de Preservação à salvaguarda da memória documental Karine Gomes Falcão Vilela e Lígia Santos da Silva Rodrigues

histórico de procedimentos e ajudar na localização do exemplar que é informado manualmente no catálogo eletrônico, além de indicar a posição de espera e se é alvo de prioridade.

\section{Segunda Etapa - Conservação e/ou Restauração;}

Uma vez selecionado, o documento segue para o LABOR para análise do estado de conservação e escolha de qual procedimento técnico o volume será submetido. A análise gera um diagnóstico que identifica e registra as prioridades. Para as obras mais danificadas é recomendado o restauro, do contrário apenas a higienização, pequenos reparos e o acondicionamento. Os objetos encontrados dentro dos livros também recebem tratamento de conservação e registro na catalogação. As técnicas e materiais empregados nas intervenções de restauro podem extrair informações sobre procedimentos físicos e químicos aos quais os livros foram submetidos como, por exemplo, quando se apaga a tinta de carimbo usada para indicar a propriedade da obra na tentativa de encobrir um furto. Todos os processos desenvolvidos no laboratório são acompanhados pelo bibliotecário da Seção Coleção Especial.

\section{Terceira Etapa - Catalogação/Inventário}

Depois de passar pelos procedimentos de conservação (higienização, restauro, pequenos reparos e acondicionamento), os exemplares seguem ao Setor de Processo Técnico da Informação onde são catalogados, classificados e indexados numa base de dados eletrônica de acesso on-line. $\mathrm{O}$ documento é descrito no nível 2, por meio das regras do Código de Catalogação Anglo-Americano AACR2 e inserido no modelo de entrada de dados no formato MARC. Na área de notas locais são detalhadas desde o estado de conservação das obras, até a descrição de dedicatórias, assinaturas, depoimentos e tantas outras informações extrínsecas ao suporte e a confecção editorial que personalizam cada exemplar como único. Nesse contexto, a Catalogação/Inventário é fundamental para no conhecimento do acervo e descrição dos exemplares resultando no melhor controle do acervo como na segurança das obras. Informações contidas no tombamento e descrição do exemplar ajudam na identificação e individualizam de livros extraviados, furtados ou roubados.

\section{Quarta Etapa - Digitalização}

Após a inclusão do título no catálogo eletrônico o documento é encaminhado à digitalização. São digitalizadas as obras que possuem demanda de acesso e sua disponibilização é mediante 
Biblioteca da Faculdade de Direito do Recife: contribuições da Política de Preservação à salvaguarda da memória documental Karine Gomes Falcão Vilela e Lígia Santos da Silva Rodrigues

consulta a lei de direito autoral. Caso esteja em domínio público ou a Biblioteca possua por escrito a autorização do autor, a obra é disponibilizada no Repositório Institucional da UFPE. As imagens geradas na digitalização são levemente tratadas, corrigidos desvios e removidas as bordas. Não são permitidas intervenções que alterem o formato original da obra, visto ser uma preocupação da Biblioteca garantir a autenticidade do documento. Estes arquivos em PDF são utilizados como cópias de acesso.

As imagens transformadas em .pdf ficam armazenadas em um computador localizado na própria sala da digitalização, além de serem criadas cópias de backup que, por motivo de segurança, são armazenadas em locais diferentes. Esse serviço de reprodução e disponibilização em meio digital permite uma maior segurança física para o acervo, pois, evita o contato com os livros, além de contribuir com a integridade intelectual da obra que passa a ter visibilidade de conteúdo e autoria fiéis a obra original.

\section{Quinta Etapa - Guarda e Manutenção}

Terminada a etapa da digitalização o documento impresso retorna ao seu local de origem na Coleção Especial, devidamente acondicionado e identificado. Após a guarda os documentos, somente deverão ser retirados em casos excepcionais ou para fins de exposição ou manutenção do acervo. Por medida de segurança, a Coleção Especial possui o acesso e a circulação restrita a servidores identificados e bolsistas acompanhados. A entrada é registrada por sistema de controle biométrico que auxilia na segurança local. A consulta as obras é realizada em local reservado fora do setor de depósito, portanto, não há contato do público externo com o acervo, salvo durante a visita dirigida que acontece mediante agendamento e é monitorada.

Ao fim das atividades previstas na Política de Preservação da CESP segue-se a manutenção preventiva que prevê o monitoramento do acervo em busca de sinais que possam requerer intervenções. Esse controle ocorre de forma espontânea durante a retirada e guarda dos exemplares e durante atividades de higienização e expansão do acervo; e de maneira previsível com o monitoramento da coleção por meio de equipamentos e materiais de uso do LABOR.

E finalmente com a conclusão da última etapa de guarda do documento, pode-se observar que o fluxo das atividades atende a uma rotina de trabalho conduzida por boas práticas e auxiliam manutenção das obras tratadas. Além disso, observou-se o envolvimento das equipes de restauradores e bibliotecários no desenvolvimento da política de preservação de maneira a somar 
experiências, estreitar laços de colaboração e assim reduzir bastante os ruídos de comunicação entre setores da Biblioteca causados pela separação física das seções de trabalho e área de formação e atuação dos profissionais.

$\mathrm{Na}$ esteira dessas ações também foi possível capacitar alunos bolsistas de Biblioteconomia que colaboram com as atividades de processamento técnico da informação, conservação e restauro de livros. Essa oportunidade sem dúvida enriquece o currículo dos alunos que passam a conviver com a prática daquilo que é ensinado na academia e acrescenta o diferencial da experiência vivida na biblioteca.

A Biblioteca de Direito, conforme visto, adota na CESP alguns métodos preventivos de preservação norteados pelas diretrizes já descritas: Registrar e divulgar documentos; Sistematizar e integrar ações técnicas e, Institucionalizar às estâncias superiores os procedimentos desenvolvidos pelas equipes da Biblioteca e LABOR. Essa institucionalização se deu com redação dos documentos, a saber:

1 - Aprovação da Resolução que disciplina o acesso à Coleção Especial, documento oficial aprovado pela instância superior da Faculdade de Direito. A Resolução é repassada ao pesquisador junto às informações de atendimento do setor e orienta quanto ao que precisa ser informado ao solicitar uma obra, quais equipamentos e objetos podem ser levados e usados na consulta às obras, horário de pesquisa entre outras informações próprias do setor;

2 - Registro dos critérios de raridade realizados por meio da publicação de uma obra² que elenca quais critérios são utilizados pela Biblioteca. Tais critérios foram guiados por padrões seguidos por outras instituições nacionais, e também aqueles de uso internacional. Além dos critérios estabelecidos pela própria Biblioteca para atender a demanda interna institucional. A edição abordar os principais elementos de identificação de obras raras de maneira a introduzir os bibliotecários iniciantes no universo bibliológico; e

3 - Aprovação de Resolução que regulamenta a digitalização das obras raras e valiosas orientando os procedimentos técnicos e estabelece quais parâmetros e recursos devem ser adotados. Faz parte da Resolução a curadoria digital para fins de preservação e a legislação referente ao direito

\footnotetext{
${ }^{2}$ VILELA, Karine Gomes Falcão et al. Obras raras e valiosas: critérios adotados pela Biblioteca da Faculdade de
} Direito do Recife. 1. ed. Recife: Ed. Universitária da UFPE, 2012. 99 p. 
autoral como prerrogativa para a disponibilidade em ambiente web sem que haja prejuízo ao direito de propriedade.

\section{Considerações finais}

Há uma vasta documentação oitocentista sobre a Biblioteca de Direito, sobre as atividades daqueles que desempenhavam a função de bibliotecário, registros produzidos por administradores e autoridades responsáveis por gerir recursos para a manutenção da Biblioteca. A exceção dos escritos de Clóvis Bevilaqua poucos são os relatos dos bibliotecários, sobre o estado real de conservação da Biblioteca, ou das atividades por eles desenvolvidas.

Com o advento do século XX, e da formação profissional do bibliotecário, tem-se o início de uma narrativa produzida pelos próprios bibliotecários. Em instituições de memória como a Biblioteca de Direito a prática de ações de preservação integram o histórico institucional de formação, manutenção e atualização de coleções que graças aos registros administrativos podem ser recuperados e permitem um novo olhar pela perspectiva dos profissionais. Ainda são carentes os estudos com maior detalhamento da rotina dos bibliotecários na adoção de medidas administrativas na gestão do acervo.

O gerenciamento de acervos documentais principalmente àqueles tidos como acervos de memória constitui um verdadeiro desafio para profissionais por requerer deles paciência monástica, olhar atento, mãos habilidosas e o cultivo de um espírito perseverante na busca por recursos humanos e financeiros necessários para atender demandas de acesso, uso e preservação da informação sem prejuízo a nenhum deles.

As coleções bibliográficas permanecem a constituir o cerne de bibliotecas universitárias e quando se trata de obras antigas, raras ou de época o tempo e a ingerência constituem alguns dos maiores vilões na luta contra a finitude dos suportes e, por conseguinte, da memória. Infelizmente a custa de sinistros, muitas vezes, passa-se a tomar ciência dos perigos que rondam esses acervos e assim, medidas de salvaguarda devem ser incorporadas a rotina de trabalho desses locais tanto para a prevenção de acidentes como também para o planejamento de ações e a tomada de decisões.

Nessa direção a Política de Preservação da Coleção Especial da Biblioteca da Faculdade de Direito do Recife foi, conforme novas demandas, técnicas e tecnologias são apresentadas. Cada uma das etapas por que o documento passa é alinhada a uma metodologia sistemática que busca 
Biblioteca da Faculdade de Direito do Recife: contribuições da Política de Preservação à salvaguarda da memória documental Karine Gomes Falcão Vilela e Lígia Santos da Silva Rodrigues

salvaguardar de várias maneiras os livros tanto na manutenção da sua integridade física e intelectual como em assegurar o direito do autor, sem perder de vista os princípios norteadores das bibliotecas pública que é o acesso e uso das obras. Adequar essa realidade de trabalho aos moldes ideais de gerenciamento de coleções especiais não é algo fácil, mas torna-se possível mediante o compromisso institucional desenvolvido por meio de boas práticas que permitam atender não apenas necessidades de conservação de documentos, uso da informação e segurança física das obras, mas também a sua valoração enquanto patrimônio histórico e cultural.

A Política de Preservação da Biblioteca de Direito, conforme visto, não se trata de um documento impresso, é uma ação que contempla áreas distintas: Ciência da Informação (Biblioteconomia, Museologia, Arquivologia), de Conservação e Restauro, Administração. Trata-se de um trabalho de natureza interdisciplinar que está em constante desenvolvimento, por ser frequentemente revisto e atualizado. Ao contrário do que apregoa o senso comum o trabalho em Bibliotecas Públicas é dinâmico e a cada dia novos desafios são impostos. Atualmente é premente a formulação de uma Política de desenvolvimento de Coleções à CESP, porque o acervo não pára de crescer, são doações de acervos, de ex-professores, ex-alunos, ex-servidores que são frequentemente encaminhados à Biblioteca. Há ainda além de obras antigas, também a aquisição de obras raras recentes. Como se sabe a antiguidade de uma obra, é apenas um dos diversos critérios que a caracterizam por rara ou valiosa.

Os livros, folhetos e periódicos que formam o acervo fundador da Biblioteca de Direito e mais aqueles antigos, de edição esgotada, com tiragem limitada, os autografados, aqueles com temas ou autores de destaque, com encadernações elaboradas, todos eles depositados na Coleção Especial cada um com seu histórico, suas marcas de proveniência, marcas de leituras, de cuidados ou mesmo de relapsos dão sentido a adoção de boas práticas de salvaguarda instituídas na Política de Preservação. São obras que requerem investimentos e sem pontuar nas avaliações subjetivas dos cursos superiores a que tanto serviram e servem, permanecem depositadas na Coleção Especial aguardam cada uma a seu tempo os cuidados necessários para cumprir o papel de guarda e memória.

\section{Referências}

UNIVERSIDADE FEDERAL DE PERNAMBUCO. Faculdade de Direito do Recife. Arquivo. Relatórios (1898-1891). Livro n. 151. Informações sobre compra de livros, encadernação e assinatura de revistas no ano de 1898. 
Biblioteca da Faculdade de Direito do Recife: contribuições da Política de Preservação à salvaguarda da memória documental Karine Gomes Falcão Vilela e Lígia Santos da Silva Rodrigues

UNIVERSIDADE FEDERAL DE PERNAMBUCO. Faculdade de Direito do Recife. Arquivo. Livro de Contratos (1884-1895). Livro n. 77. No ano de 1890 há o registro de encadernação de livros.

ARAÚJO, Carlos Alberto Ávila. O que é a Ciência da Informação, Informação \& Informação, Londrina, v. 19, n. 1, p. 01-30, jan./abr. 2014.

BRADLEY, Susan M. Os objetos tem vida finita? In: MENDES, Marylka et al. Conservação: conceitos e práticas. Rio de Janeiro, 2001. p. [15]-34.

CONWAY, Paul. Preservação no Universo Digital. 2. ed. Rio de Janeiro: Arquivo Nacional, 2001. 32 p. (Conservação preventiva em bibliotecas e arquivos). Disponível em: http://arqsp.org.br/wpcontent/uploads/2017/07/52.pdf. Acesso em: 20 abr. 2018.

DODEBEI, Vera. Cultura, memória, tecnologia: a preservação do conhecimento nas sociedades contemporâneas. In: DUARTE, Zeny. (org.) Arquivos, bibliotecas e museus: realidades de Portugal e Brasil. Salvador: EDUFBA, 2013. p. 227-236.

DODEBEI, Vera Lúcia; AZEVEDO NETTO, Carlos Xavier. Informação e Memória: Trajetória do GT 10 da Ancib e o impacto dos estudos culturais na Cl. In: OLIVEIRA, Eliane Braga de; RODRIGUES, Georgete Medleg (org.). Memória: interfaces no campo da informação. Brasília: Editora Universidade de Brasília, 2017. p. 53

ECO, Umberto. A memória vegetal e outros escritos sobre bibliofilia. Tradução de Joana Angélica d'Àvila. Rio de Janeiro: Record, 2010. 271 p.

GREENHALGH, Raphael Diego. Segurança contra roubo e furto de livros raros: uma perspectiva sob a ótica da economia do crime e da teoria da dissuasão. 2014. Tese (Doutorado em Ciência da Informação) Universidade de Brasília, Brasília, 2014. 2 v.

LE GOFF, Jacques. Documento/monumento. In: História e memória. 5. ed. Campinas: Editora da Unicamp, 2003. p.533-535.

LINO, Lucia Alves da Silva; HANNESCH, Ozana; AZEVEDO, Fabiano Cataldo de. Política de preservação no gerenciamento de coleções especiais: um estudo de caso no Museu de Astronomia e Ciências Afins. Anais da Biblioteca Nacional, Rio de Janeiro, v. 123, p. 59-76, 2003.

MORAES, Rubens Borba de. Livros e bibliotecas no Brasil colonial. 2. ed. Brasília: Briquet Lemos, 2006.

PINHEIRO, Ana Virginia. Metodologia para inventário de acervo antigo. Anais da Biblioteca Nacional, Rio de Janeiro, v. 123, p. 9-33, 2003. 


\section{Notas}

1 Nas citações do século XIX, serão mantidas a ortografia, a pontuação e a sintaxe originais.

2 Ao longo do texto será adotada as formas abreviadas e com iniciais maiúsculas ‘Biblioteca de Direito' e 'Biblioteca' para referir-se à Biblioteca da Faculdade de Direito do Recife.

3 Arquivo da Faculdade de Direito do Recife. Oficios remetidos à Faculdade de Direito. 1857-1859.Ministério dos Negócios do Império. Rio de Janeiro, 12 outubro 1857.

${ }^{4}$ Nas pesquisas desenvolvidas durante os respectivos mestrados das autoras essa informação não foi localizada.

5 Os Estatutos preconizados pelo Decreto n. 1.386, de 28 de abril de 1854, estabelecem que "os actuaes Cursos Juridicos serão constituidos em Faculdades de Direito; designando-se cada huma pelo nome da Cidade, em que tem, ou possa ter assento"393. Desse modo, o Curso Jurídico passa a ser designado Faculdade de Direito do Recife.

6 A Lei de criação do Gabinete Português de Leitura é de 1850; a Biblioteca Pública Provincial, depois, Biblioteca Pública do Estado, é de 1856.

7 Ordem com ações e influência na vida cultural, econômica e política da Província Pernambucana, em meados do século XVIII.

8 Foram localizados dois registros de encadernação no Arquivo da Faculdade de Direito do Recife. O primeiro no Livro de Contratos (1884-1895). Livro n. 77. No ano de 1890 no qual há o registro de encadernação de livros. E o segundo nos Relatórios (1898-1891). Livro n. 151. Com dados de compra de livros, encadernação e assinatura de revistas, em 1898.

9 Apesar de na atualidade, o termo genérico “obras raras”, não ser adotado na Biblioteca de Direito aqui será usado para facilitar a leitura do texto, visto que o termo abrange uma diversidade de tipologia documental, livros, periódicos, folhetos, avisos, manuscritos, fotografias, cartazes, folhas soltas. 